\section{Validation of the Brazilian Version of the RMS Tactile Scale (B-RMS-TS)}

\author{
Lucas Rodrigues Teles (D1, Matheus França Perazzo (D), Saul Martins \\ Paiva (D1, Raghavendra Shetty (1)2,3, Rudolf Huebner (1) 4, Paulo \\ Antônio Martins-Júnior (D1, Júnia Maria Serra-Negra (D1.
}

This study aimed to validate the Brazilian version of the RMS Tactile Scale (BRMS-TS) in children and adolescents with visual impairment. Ten visually impaired children and adolescents between 10 and 17 years old of an Educational Center for Visually Impaired People answered the verbalized Dental Anxiety Scale (DAS), and the DAS in Braille to evaluate their dental anxiety levels. B-RMS-TS construct validity was assessed by convergent and discriminant validity. Convergent validity was tested in two ways: Pearson's correlation between the B-RMS-TS and the overall anxiety question; Pearson's correlation between B-RMS-TS and verbalized DAS and DAS in Braille. B-RMS-TS reliability was measured by internal consistency (Cronbach's alfa and McDonald's omega) and test-retest reliability (ICC). BRMS-TS was moderately correlated to the overall anxiety question $(r=0.493 ; p=0.147)$. B-RMS-TS showed excellent correlation with verbalized DAS $(r=0.971 ; p<0.001)$ and DAS in Braille $(r=0.934 ; p<0.011)$. B-RMS-TS was able to discriminate dental anxiety levels between male and female $(p=0.008)$. The B-RMS-TS demonstrated excellent reliability (Cronbach's alpha $=0.661$, McDonald's omega $=0.700$ and $I C C=0.987 ; 95 \% \mathrm{Cl}=0.817-$ 0.999 ). B-RMS-TS is valid and reliable to measure dental anxiety levels in Brazilian children and adolescents with visual impairment.

\author{
1Department of Pediatric Dentistry, Federal \\ University of Minas Gerais, Belo Horizonte, Bra- \\ zil. \\ 2Department of Clinical Sciences, College of \\ Dentistry, Ajman University, Ajman, United \\ Arab Emirates \\ 3Center of Medical and Bio-allied Health \\ Sciences Research, Ajman University, Ajman, \\ United Arab Emirates \\ 4Department of Mechanical Engineering, \\ Laboratory of Bioengineering, Federal \\ University of Minas Gerais, Belo Horizonte, \\ Brazil. \\ Correspondence: Júnia Maria Serra-Negra, PhD \\ Department of Pediatric Dentistry, Federal \\ University of Minas Gerais; Av. Antonio Carlos, \\ 6627, Pampulha, Belo Horizonte, Minas Gerais, \\ Brazil; E-mail: juniaserranegra@hotmail.com
}

Key Words: adolescent, behavior, child, dental anxiety, vision disorders

\title{
Introduction
}

Vision is the most dominant of the five human senses and it has a vital role in all stages of the human life course (1). For example, newborns depend on the vision to recognize and respond to parents and toddlers use vision to master balance and learn to walk. Children need the vision to be able to read, learn and to socialize. The adults depend on the vision to participate in the workforce and to maintain their social contact and independence (1).

At least 2.2 billion people worldwide have a visual impairment or blindness (1), from which 1.4 million are children (2). In Brazil, it is estimated that about 6.5 million people present some degree of visual impairment (3). In this context, the literature highlights the challenge for dental professionals to assist patients with special needs, as well as the challenge of dealing with dental anxiety of patients during treatment $(4,5)$.

Dental anxiety has already been assessed in children through physiological measures, such as pulse and muscle tension (6,7). Psychological tests, such as Corah's Dental Anxiety Scale (DAS) (8), are highly popular due to its reliability and ease of application. However, these scales were developed to be applied in individuals with normal vision. Studies have demonstrated the difficulties of visually impaired individuals to deal with their own oral health care $(9,10)$. The communication between dental professionals and visually impaired children and adolescents can also be compromised since one of the most used behavioral management techniques, the "Tell-Show-Do", cannot be used appropriately simple because visually impaired children cannot visualize the step "Show" (11). Therefore, it is important to use patient report outcome measures (PROMS), subjective instruments that evaluate patients' health condition from their own perspective (12), to allow the measurement and recognition of the emotions of visually impaired children related to dental treatment. This will help dental professionals to create strategies to effective behavior guidance aimed at promoting the health and comfort of these patients (13). 
The RMS Tactile Scale (RMS-TS) was created with the objective of measuring the dental anxiety levels of children and adolescents with visual impairment (14). This innovative scale prioritizes the tactile function of the visually impaired children and it was designed to be applied with the DAS (14). The RMSTS has five three-dimensional facial expressions ranging from " 1 - not anxious" to " 5 - extremely anxious" as response options. The validation of the RMS-TS for Brazil will enable dental professionals to identify and measure the dental anxiety levels of Brazilian children and adolescents with visual impairment in an inclusive way. In addition, it will open up new perspectives for the execution of innovative political and clinical actions of an inclusive nature.

The aim of this study was to validate the Brazilian version of the RMS Tactile Scale (B-RMS-TS) in children and adolescents with visual impairment.

\section{Materials and Methods}

This study was carried out according to the Consensus-based Standards for the selection of health Measurement INstruments (COSMIN) checklist $(15,16)$.

\section{Ethical issues}

This study was carried out in compliance with the Declaration of Helsinki. The study was approved by the Human Research Ethics Committee of Federal University of Minas Gerais, Brazil (Protocol number: 13555219.6.0000.5149). Parents/guardians signed an informed consent form agreeing with the participation of their children in the research. An agreement term was printed in Braille to allow participants to read and give their consent to participate in the study. Participation was voluntary.

\section{Study design and eligibility criteria}

A validation study with a cross-sectional design was carried out with a convenience sample of visually impaired children and adolescents selected in a reference center for visually impaired individuals, the São Rafael Institute located at Belo Horizonte, Minas Gerais, Brazil The city has a territorial area of $331,401 \mathrm{~km}^{2}$ and an estimated population of 2,513,451 inhabitants (3).

Visually impaired children and adolescents between 10 and 17 years of age with normal development reported by parents/guardians were included. All participants had previous experience of dental appointment. Children and adolescents with other types of disabilities and/or syndromes (motor, intellectual or hearing) evaluated by parents, teachers and/or other health professionals, and those whose mother tongue was other than Brazilian Portuguese were excluded.

\section{Dental anxiety scales}

Dental anxiety scale

The Dental Anxiety Scale (DAS) was developed in the United States to measure the dental anxiety levels and it has already been validated for use in Brazil $(8,13)$. DAS has four questions with five possible answers: "1 - not anxious"; "2 - slightly anxious"; "3 - quite anxious"; "4 - very anxious"; "5 - extremely anxious". The scores of each answer are summed to achieve a total score, which varies from 4 to 20 . Total scores of 15 or above indicate highly dental anxiety $(8,13)$. The DAS scale is originally applied in a verbalized format, in which a professional reads the questions and answer options for the respondent.

\section{DAS in Braille}

A Brazilian version of the DAS was printed in Braille, using an Everest Braille printer (Tecassistiva, Brazil) in the Braille Press sector, Pedagogical Support Center for People with Visual Disabilities (CAP), located at the São Rafael Institute, Brazil.

\section{RMS Tactile Scale}

The RMS-TS was developed in India to measure dental anxiety levels of visually impaired children and adolescents. The scale uses the questions from the DAS and has a row of five three-dimensional faces fabricated in fiber that simulate facial expressions of "1 - not anxious"; "2 - slightly anxious"; "3 quite anxious"; "4 - very anxious"; " 5 - extremely anxious" children. Smiles, tears during crying and other details that express emotion are differentiated by elevations and depressions in the face. Scores are summed to achieve a total score. 


\section{Brazilian version of the RMS-TS (B-RMS-TS)}

To develop the B-RMS-TS, a complete facial scanning of a Brazilian young male was performed using an EinScan-Pro+ Handheld Scanner (Shining 3D, China). All facial expressions of the RMS-TS scale were simulated. Adjustments in the expressions were performed using the Maxymiser (Autodesk, USA). The faces were printed on a 3D printer (Sothi 3D Aip A3, Brazil) using Acrylonitrile Butadiene Styrene (ABS) filaments. The finishing was done with sandpaper 80 and 220 bathed in water. Then, the faces were dyed with a brown varnish and dried in a conventional oven at $20{ }^{\circ} \mathrm{C}$ (Figure. 1).
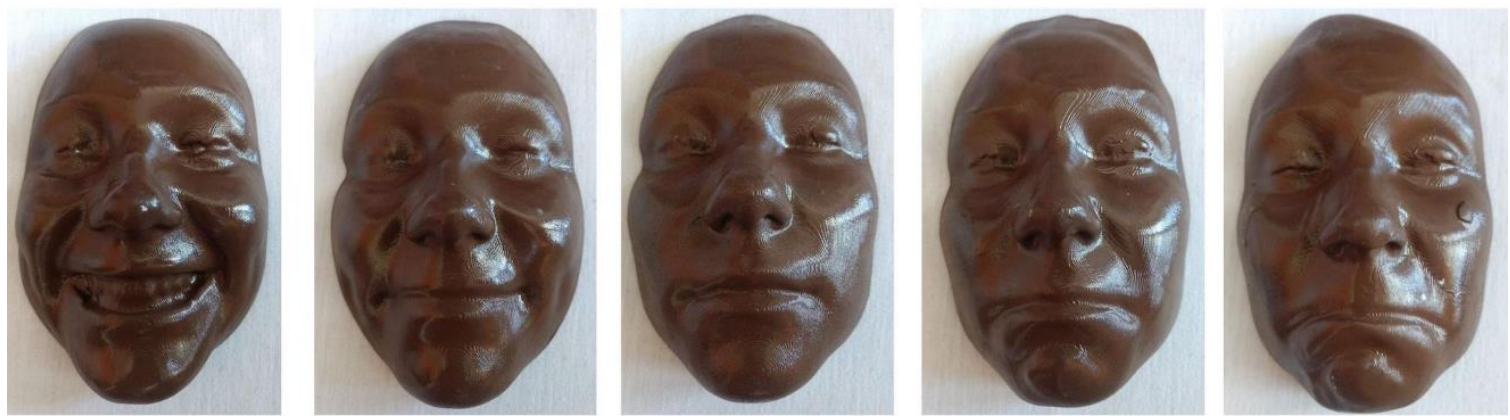

Figure 1. The Brazilian version of the RMS Tactile Scale (B-RMS-TS).

\section{Data collection}

Data collection took place between February and March 2020. A single trained researcher administered the scales to participants. Each participant was interviewed individually in a separate room at São Rafael Institute. Demographic data such as age, gender and degree of visual impairment of the participants were collected. First, each child or adolescent answered a question about their overall level of anxiety: "how anxious do you consider yourself?". Response options ranged from "0 - not anxious" to "3 - extremely anxious".

The dental anxiety levels were measured using three scale: the verbalized DAS, the B-RMS-TS and the DAS in Braille. Initially, children and adolescents received verbal guidance explaining each scale. The B-RMS-TS was delivered 10 minutes before the official application to allow participants' adaptation with the scale (14).

The scales were applied sequentially with a 3-minutes interval between each one. First, the verbalized DAS scale was applied and, after each question, the participants were asked to chose one of the answer options. Then, the B-RMS-TS was applied, using the same questions on the DAS scale, however, the participants responded by choosing the three-dimensional face that best represented their feelings. Finally, the DAS in Braille was applied and the participants read the questions, chose the answer options and informed the choice to the researcher. After applying the scales, a verbal question asked about the participant's preference in relation to the scales, with the following answer options: verbalized DAS; B-RMS-TS, DAS in Braille or none of the scales.

After seven days, the test-retest was performed with $30 \%$ of the participants $(n=3)$, who were randomly selected to respond to the scales again, following the same application methodology.

\section{Statistical analysis}

Data analysis was performed using the Statistical Package for Social Sciences program (SPSS for Windows, version 24.0, SPSS Inc., Chicago, IL, USA). Initially, descriptive analyzes were performed. The Shapiro-Wilk test was applied to verify the normality of data distribution, indicating normal data distribution. The level of significance for the validity and reliability analyses was set to $5 \%$.

The B-RMS-TS construct validity was assessed by means of convergent and discriminant validity. Convergent validity was tested in two ways: Pearson's correlation between the B-RMS-TS and the overall anxiety question; Pearson's correlation between B-RMS-TS and verbalized DAS and DAS in Braille. Correlation values were categorized as follows: 0.00-0.40 weak correlation; 0.41-0.60 moderate correlation; $0.61-0.80$ good correlation; and 0.81-1.00 excellent correlation (17). Values of $r>0$ indicate the existence of convergent validity (18). To determine the discriminant validity, differences between the total scores of the verbalized DAS, B-RMS-TS and DAS in Braille in male and female participants were tested using the t-test for independent samples.

The B-RMS-TS reliability was evaluated through internal consistency and test-retest reliability. Internal consistency was assessed by Cronbach's alpha (19) and McDonald's s omega (20). Test-retest 
reliability was analyzed using the intraclass correlation coefficient (ICC). The ICC was categorized as follows: $0.00-0.40$ weak correlation; $0.41-0.60$ moderate correlation; $0.61-0.80$ good correlation; and $0.81-1.00$ excellent correlation (17).

\section{Results}

Ten children and adolescents with visual impairment participated in the study, being $60 \%(n=6)$ male. Response rate was $100 \%$. The mean age of the participants was $13.6 \pm 1.41$ years. Half of the sample had a low vision $(50 \% ; n=5)$, while the other half had blindness $(50 \% ; n=5)$. Most participants $(90 \% ; n=9)$ declared to have some level of overall anxiety. The mean scores of the scales were: verbalized DAS $=9.00 \pm 3.30$, B-RMS-TS $=9.80 \pm 3.26$ and DAS in Braille $=9.44 \pm 2.79$.

In the analysis of convergent validity, there was a moderate correlation between the B-RMS-TS and the overall anxiety question $(r=0.493 ; p=0.147)$ and excellent correlations between B-RMS-TS and verbalized DAS $(r=0.971 ; p<0.001)$ and between B-RMS-TS and DAS in Braille $(r=0.934 ; p<0.001)$ (Table $1)$. In the discriminant validity, female participants reported significantly higher dental anxiety levels than males on all scales $(p<0.05)$ (Table 2$)$.

Table 1 . Convergent validity of the Brazilian version of the RMS Tactile Scale (B-RMS-TS).

\begin{tabular}{lccccc}
\hline Scales & Mean (SD) & Possible range & Observed range & $\mathrm{r}^{*}$ & $\mathrm{p}$ \\
\hline Overall anxiety & $2.60(0.84)$ & $1-4$ & $1-4$ & 0.493 & 0.147 \\
Verbalized DAS & $9.00(3.30)$ & $4-20$ & $4-16$ & 0.971 & $<0.001$ \\
B-RMS-TS & $9.80(3.26)$ & $4-20$ & $4-16$ & - & - \\
DAS in Braille & $9.44(2.79)$ & $4-20$ & $6-15$ & 0.934 & $<0.001$ \\
\hline
\end{tabular}

*Pearson's correlation in relation to B-RMS-TS;

SD: Standard deviation;

DAS: Dental Anxiety Scale.

Table 2. Discriminant validity of the Brazilian version of the RMS Tactile Scale (B-RMS-TS).

\begin{tabular}{|c|c|c|c|}
\hline \multirow[b]{2}{*}{ Scales } & \multicolumn{2}{|c|}{ Sex of the participants } & \multirow[b]{2}{*}{$\mathrm{p}^{*}$} \\
\hline & $\begin{array}{c}\text { Male } \\
\text { Mean (SD) }\end{array}$ & $\begin{array}{c}\text { Female } \\
\text { Mean (SD) }\end{array}$ & \\
\hline Verbalized DAS & $7.00(1.67)$ & $12.00(2.83)$ & 0.007 \\
\hline B-RMS-TS & $7.83(2.14)$ & $12.75(2.22)$ & 0.008 \\
\hline DAS in Braille & $7.80(1.30)$ & $11.50(2.89)$ & 0.036 \\
\hline
\end{tabular}

\footnotetext{
"t-test for independent samples;

SD: Standard deviation;

DAS: Dental Anxiety Scale.
}

In B-RMS-TS reliability, the Cronbach's alpha and McDonald's omega coefficients were 0.66 and 0.70 , respectively. The ICC value was $0.987(95 \% \mathrm{Cl}=0.817-0.999)$, indicating excellent test-retest reliability.

Most participants $(70 \% ; n=7)$ declared a preference for B-RMS-TS. The testimonials of children and adolescents who preferred B-RMS-TS are displayed in table 3. 
Table 3. Testimonials of the participants about their personal preference for the Brazilian version of the RMS Tactile Scale (B-RMS-TS).

$\begin{array}{ll}\text { Participant } & \text { Testimonial }\end{array}$

\begin{tabular}{ll}
\hline 1 & "It's a nicer feel, easy to answer" \\
& "When I was touching, I thought it was a lot better and I thought it matched me a lot \\
more" & "I find it more interactive, more tactful and the person with visual impairment supplies \\
the visual impairment with touch" & "I enjoyed touching the faces, choosing the faces and talking about how I feel" \\
3 & "I like to touch and feel the things" \\
5 & "I liked it and found it easy" \\
\hline 7 & "I really liked the face that smiled, I like happy things" \\
\hline
\end{tabular}

\section{Discussion}

This study aimed to validate the B-RMS-TS for measuring the dental anxiety levels in Brazilian children and adolescents with visual impairment. Validity and reliability are two fundamental elements in the evaluation of a measurement instrument (21). The main finding of this study is that, consistent with the original study (14), B-RMS-TS proved to be valid and reliable for measuring the dental anxiety levels of Brazilian children and adolescents with visual impairment.

Vision is an important sensory function and, when it is presented a limited way, it can significantly compromise life experiences (1). Visually impaired people have difficulties in caring for oral health, resulting in a high prevalence of oral health problems, such as dental caries (10). In addition, dental professionals may face difficulties in assisting people with visual impairments, which can jeopardize the course of their treatment $(22,23)$. Thus, the B-RMS-TS can be considered as a PROM that could assist in a better communication between professionals and patients, allowing more comfortably consultations for these individuals and enhancing the professional-patient relationship $(12,14)$.

Validity is related to the extent to which a scale measures what it is intended to measure. A moderate correlation was found between the B-RMS-TS and the overall anxiety question. A study demonstrated that it is expected to find moderate to good correlations when comparing scales with global questions (17). Although $90 \%$ of the participants declared some level of overall anxiety, the mean scores of the scales were below 10, indicating that, in general, the participants had low dental anxiety levels. In addition, the excellent correlations between the B-RMS-TS and the verbalized DAS scales and the DAS in Braille are similar to those found in the original RMS-TS scale (14), showing the convergent validity of the B-RMS-TS. Significant differences were found in the dental anxiety levels between the male and females, demonstrating the ability of the B-RMS-TS to discriminate the dental anxiety levels between these two groups. Altogether, the results of convergent and discriminant validity confirm the construct validity of the B-RMS-TS.

Reliability is related to the ability of a scale to measure consistently. The Cronbach's alfa and McDonald's omega values suggested that the B-RMS-TS has adequate internal consistency. Although the literature discusses that alpha values greater than 0.70 are considered acceptable, alpha may show lower values in scales with few items and in studies with homogeneous samples (24). On the other hand, McDonald's coefficient omega, which is based on a congeneric model, showed satisfactory values considering that cut-off point (20). Besides, the B-RMS-TS showed an excellent test-retest, indicating the high stability of the scale. There is no consensus on the exact interval period required for retest, since recommend intervals range from two days to a month (25). In the present study, the retest was performed after an interval of seven days, which is within the ideal period (25). Also, there is no consensus about the sample size estimation for test-retest, with percentages ranging from 5\% to $100 \%$ 
of participants (26-28). In this study, we retested $30 \%$ of the sample, which is in agreement with a previous validation study (28). In summary, these data suggest that the B-RMS-TS is reliable to measure consistently the dental anxiety levels of visually impaired children and adolescents in Brazil.

Most participants preferred to use B-RMS-TS than the other scales. Their testimonials highlights the importance of this scale in their feeling of inclusion. This finding is in agreement with the data from the development study of the RMS-TS scale, in which $63 \%$ of the Indian participants also preferred the three-dimensional scale (14). From these findings, it can be suggested that the B-RMS-TS may benefit patients with visual impairment with a better assisted dental treatment.

The present study takes into account some limitations. Although there is no consensus about recommendations on sample size for validation studies, the number of participants was limited, even it was carried out in a regional reference center for people with visual impairments. Nevertheless, considering the accurate tactile capacity of visually impaired individuals, as well as the oral problems associated with this population, the validation of B-RMS-TS can greatly favor the professional-patient relationship. The development of studies on behavioral and oral health factors in individuals with visual impairment can serve as a basis for the construction of inclusive political and clinical actions to improve the health conditions of this group.

The B-RMS-TS is valid and reliable for measuring the dental anxiety levels in Brazilian children and adolescents with visual impairment.

\section{Acknowledgments}

This study was supported by the Federal University of Minas Gerais (UFMG), Conselho Nacional de Desenvolvimento Científico e Tecnológico - CNPq, and Coordenação de Aperfeiçoamento de Pessoal de Nivel Superior - Brasil (CAPES) - Finance Code 001.

\section{Resumo}

Este estudo objetivou validar a versão brasileira da escala tátil RMS (B-RMS-TS) em crianças e adolescentes com deficiência visual. Dez crianças e adolescentes deficientes visuais entre 10 e 17 anos de idade de um Centro Educacional para Pessoas Deficientes Visuais responderam a Dental Anxiety Scale (DAS) verbalizada, e a DAS em Braille para avaliar seus níveis de ansiedade odontológica. A validade de construto da B-RMS-TS foi avaliada pela validade convergente e discriminante. A validade convergente foi testada em duas maneiras: correlação de Pearson entre a B-RMS-TS e a questão geral de ansiedade; correlação de Pearson entre a B-RMS-TS e a DAS verbalizada e a DAS em Braille. A confiabilidade da BRMS-TS foi mensurada pela consistência interna (alfa de Cronbach e ômega de McDonald).) e confiabilidade teste-reteste (CCI). A B-RMS-TS foi correlacionada moderadamente à questão geral de ansiedade $(r=0,493 ; p=0,147)$. A B-RMS-TS mostrou correlação excelente com a DAS verbalizada $(r=0,971 ; p<0,001)$ e com a DAS em Braille $(r=0,934 ; p<0,011)$. A B-RMS-TS foi capaz de discriminar níveis de ansiedade odontológica entre meninos e meninas $(p=0,008)$. A B-RMS-TS demonstrou confiabilidade excelente (alfa de Cronbach $=0,661$, ômega de $M c D o n a l d=0,700$ e $C C l=0,987 ; 95 \% \mathrm{IC}=0,817-0,999$ ). A BRMS-TS é válida e confiável para mensurar níveis de ansiedade odontológica em crianças e adolescentes brasileiros com deficiência visual. 


\section{References}

1. World Health Organization. World report on vision. Available at: www.who.int/publicationsdetail/world-report-on-vision, 2019.

2. Shetty V, Hegde AM, Bhandary S, Rai K. Oral health status of the visually impaired children--a south Indian study. J Clin Pediatr Dent 2010;34:213-216.

3. IBGE, I. Censo demográfico 2010. IBGE: Instituto Brasileiro de Geografia e Estatística, 2010.

4. Tagelsir A, Khogli AE, Nurelhuda NM. Oral health of visually impaired schoolchildren in Khartoum State, Sudan. BMC Oral Health 2013;13:33.

5. Bagattoni S, Lardani L, Gatto MR, Giuca MR, Piana G. Effects of audiovisual distraction in children with Down syndrome during dental restorations: a randomised clinical trial. Eur J Paediatr Dent 2020;21:153-156.

6. Hembrecht EJ, Nieuwenhuizen J, Aartman IH, Krikken J, Veerkamp JS. Pain-related behaviour in children: a randomised study during two sequential dental visits. Eur Arch Paediatr Dent 2013;14:3-8.

7. Zhu M, Yu H, Xie B, Li H, He 0 , Li H, et al. Experiential learning for children's dental anxiety: a cluster randomized trial. BMC Oral Health 2020;20:216.

8. Corah NL. Development of a dental anxiety scale. J Dent Res 1969;48:596.

9. Debnath A, Srivastava BK, Shetty P, Eshwar S. New Vision for Improving the Oral Health Education of Visually Impaired Children- A Non Randomized Control Trial. J Clin Diagn Res 2017;11:ZC29-ZC32.

10. Suresan V, Das D, Jnaneswar A, Jha K, Kumar G, Subramaniam GB. Assessment of dental caries, oral hygiene status, traumatic dental injuries and provision of basic oral health care among visually impaired children of Eastern Odisha. J Indian Soc Pedod Prev Dent 2017;35:284-290.

11. Costa FDS, Neves LB, Bonow MLM, Azevedo MS, Schardosim LR. Effectiveness of an educational strategy on oral health of visually impaired children. RFO UPF 2012;17:12-17.

12. Perazzo MF, Serra-Negra JM, Firmino RT, Pordeus IA, Martins-Júnior PA, Paiva SM. Patientcentered assessments: how can they be used in dental clinical trials? Braz Oral Res 2020;34:e075.

13. Torriani DD, Teixeira AM, Pinheiro R, Goettems ML, Bonow MLM. Cross-cultural adaptation of instruments to assess anxiety and behavior in children's dental treatment. Arq Odontol 2008;44:17-23.

14. Shetty RM, Gadekar TR. RMS tactile scale: An innovative tactile anxiety scale for visually impaired children. J Indian Soc Pedod Prev Dent 2018;36:76-81.

15. Terwee CB. COSMIN checklist with 4-point scale. Cosmin. 2011.

16. Paiva SM, Perazzo MF, Ortiz FR, Pordeus IA, Martins-Júnior PA. How to Select a Questionnaire with a Good Methodological Quality? Braz Dent J 2018;29:3-6.

17. Terwee $C B$, Bot SD, de Boer MR, van der Windt DA, Knol DL, Dekker J, et al. Quality criteria were proposed for measurement properties of health status questionnaires. J Clin Epidemiol 2007;60:34-42.

18. Wilson PM, Rodgers WM. The relationships between exercise motives and physical self-esteem in female exercise participants: An application of self-determination theory. J Appl Biobehav Res 2002;7:30-43.

19. Cronbach L. Coefficient alpha and the internal ture of tests. Psychomerika 1951;16:297-334.

20. Hayes AF, Coutts JJ. Use Omega Rather than Cronbach's Alpha for Estimating Reliability. But... Commun Methods Meas 2020;14:1-24.

21. Tavakol M, Dennick R. Post-examination analysis of objective tests. Med Teach 2011;33:447458.

22. Liu L, Zhang Y, Wu W, He M, Lu Z, Zhang K, et al. Oral health status among visually impaired schoolchildren in Northeast China. BMC Oral Health 2019;19:63.

23. Jain A, Gupta J, Aggarwal V, Goyal C. To evaluate the comparative status of oral health practices, oral hygiene and periodontal status amongst visually impaired and sighted students. Spec Care Dentist 2013;33:78-84.

24. Tavakol M, Dennick R. Making sense of Cronbach's alpha. Int J Med Educ 2011;2:53-55.

25. Norquist JM, Girman C, Fehnel S, DeMuro-Mercon C, Santanello N. Choice of recall period for patient-reported out-come (PRO) measures: criteria for consideration. Qual Life Res 2012;21:1013-1020.

26. Wright WG, Spiro A 3rd, Jones JA, Rich SE, Garcia RI. Development of the Teen Oral HealthRelated Quality of Life Instrument. J Public Health Dent 2017;77:115-124.

27. Firmino RT, Granville-Garcia AF, McGrath $C P$, Bendo $C B$, Ferreira FM, Paiva SM. Validation for Brazilian Portuguese language of the Hong Kong Oral Health Literacy Assessment Task for Paediatric Dentistry (BOHLAT-P). Int J Paediatr Dent 2020;30:234-243. 
28. He S, Wang J. Validation of the Chinese version of the Caries Impacts and Experiences Questionnaire for Children (CARIES-QC). Int J Paediatr Dent 2020;30:50-56. 